\title{
FNK MODEL OF CRACKING RATE CALCULUS FOR A VARIABLE ASYMMETRY COEFFICIENT
}

\author{
ROŞCA Vâlcu \\ Professor, Ph.D., Faculty of Mechanics/Department of Applied Mechanics and Civil Constructions, \\ University of Craiova, Craiova, Romania, rosca_valcu@yahoo.com \\ MIRIŢOIU Cosmin Mihai \\ Assistant, Ph.D, Faculty of Mechanics/ Department of Applied Mechanics and Civil Constructions, \\ University of Craiova, Craiova, Romania, miritoiucosmin@yahoo.com
}

\begin{abstract}
In the process of materials fracture, a very important parameter to study is the cracking rate growth da/dN. This paper proposes an analysis of the cracking rate, in a comparative way, by using four mathematical models:1 - polynomial method, by using successive iterations according to the ASTM E647 standard; 2 - model that uses the Paris formula; 3 - Walker formula method; 4 - NASGRO model or Forman Newman - Konig equation, abbreviated as FNK model. This model is used in the NASA programs studies. For the tests, CT type specimens were made from stainless steel, V2A class, 10TiNiCr175 mark, and loaded to a variable tensile test axial - eccentrically, with the asymmetry coefficients: $R=0.1,0.3$ and 0.5 ; at the $213 \mathrm{~K}\left(-60^{\circ} \mathrm{C}\right)$ temperature. There are analyzed the cracking rates variations according to the above models, especially through FNK method, highlighting the asymmetry factor variation.
\end{abstract}

Key words: fracture mechanics, crack, asymmetry factor, stress intensity factor

\section{Introduction}

The functioning in variable loadings regime of a product may lead to micro-cracks appearance in the material's mass. These, and the ones that already exist from the product elaboration process, are extending, combine between them, leading to a main crack which its evolution in time may lead to the product breakage. The process of material fracture can be followed and controlled by analyzing a basis parameter of "Fracture mechanics" named as the crack propagation rate. This is marked with da/dN, and sometimes with $\mathrm{da} / \mathrm{dt}$, and represents the defect (crack) length variation a at a variable loading cycle. The main parameters that define a fatigue loading, in the case of tensile - eccentrically loading, are the limit stresses, meaning $\sigma_{\min }$ and $\sigma_{\max }$, respectively the loading asymmetry coefficient, meaning $\mathrm{R}=\sigma_{\min } / \sigma_{\max }$. The parameter $\underline{\Delta \mathrm{K}}$ will be determined, which represents the stress intensity factor variation with an empiric relation given in the next paragraph. By highlighting the crack variation length $\Delta$ a there will be finally determined the growth cracking length (FCG - Fatigue Crack Growth), marked with da/dN (or $\mathrm{da} / \mathrm{dt}$ ) and means the crack variation length a produced at a loading fatigue cycle. In the "Fracture Mechanics" domain there are proposed many calculus relations for the cracking rate calculus, from which we will present four variants empirically established:

1- Sequentially polynomial method according to the American standard ASTM E647;

2- Paris formula method;

3- Walker formula method;

4- FNK method (Forman - Newton - Konig), known as NASGRO.

For the fracture study through fatigue, in general there is used the cracking rate variation $(\mathrm{da} / \mathrm{dN})$ versus the stress intensity factor $(\Delta \mathrm{K})$. This analysis is advantageous because the stress intensity factor depends not only on the loading stress variation $(\sigma)$, but also by the current crack length, being proportional with the term $\Delta \sigma \cdot \sqrt{\pi \cdot a}$. The crack propagation rate variation graphic $(\mathrm{d} a / \mathrm{dN})$ versus the stress intesity factor variation $(\Delta \mathrm{K})$ is a sigmoid which generally contains an almost linear gap and represents the stable propagation crack, [4], [6].

\section{Experiments}

For the proposed experimental study there were made some CT type samples from cylindrical bar with 60 $\mathrm{mm}$ diameter $\mathrm{R}-\mathrm{C}$ positioned, figure 1 . The material was a stainless steel 10TiNiCr175. The samples were 
tested to oscillatory positive, tensile eccentrically, loading. The three asymmetry coefficients $\mathrm{R}=0.1$, $\mathrm{R}=0.3$ and $\mathrm{R}=0.5$ were used for fatigue loading. The tests were made on a pulsatory hydraulic device with a cryogenic chamber mounted, figure 2 .

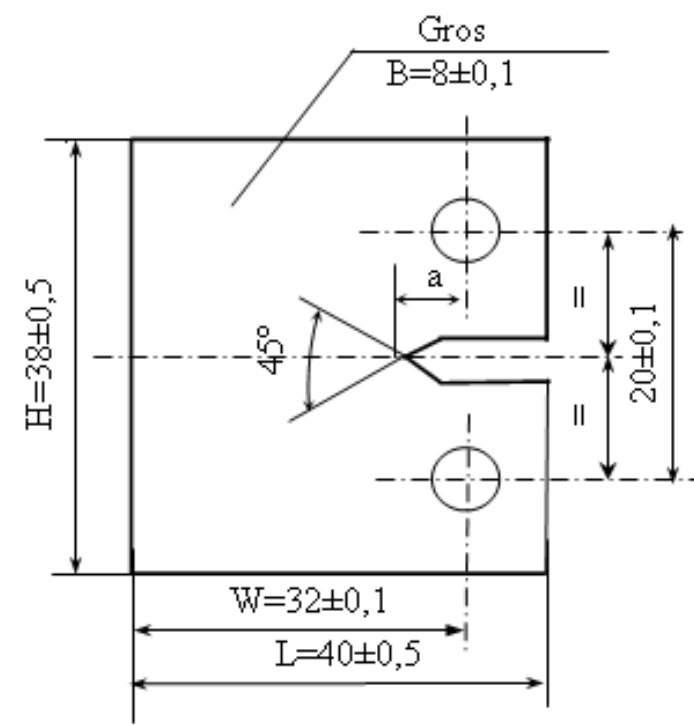

Figure 1: The CT specimens with side notch

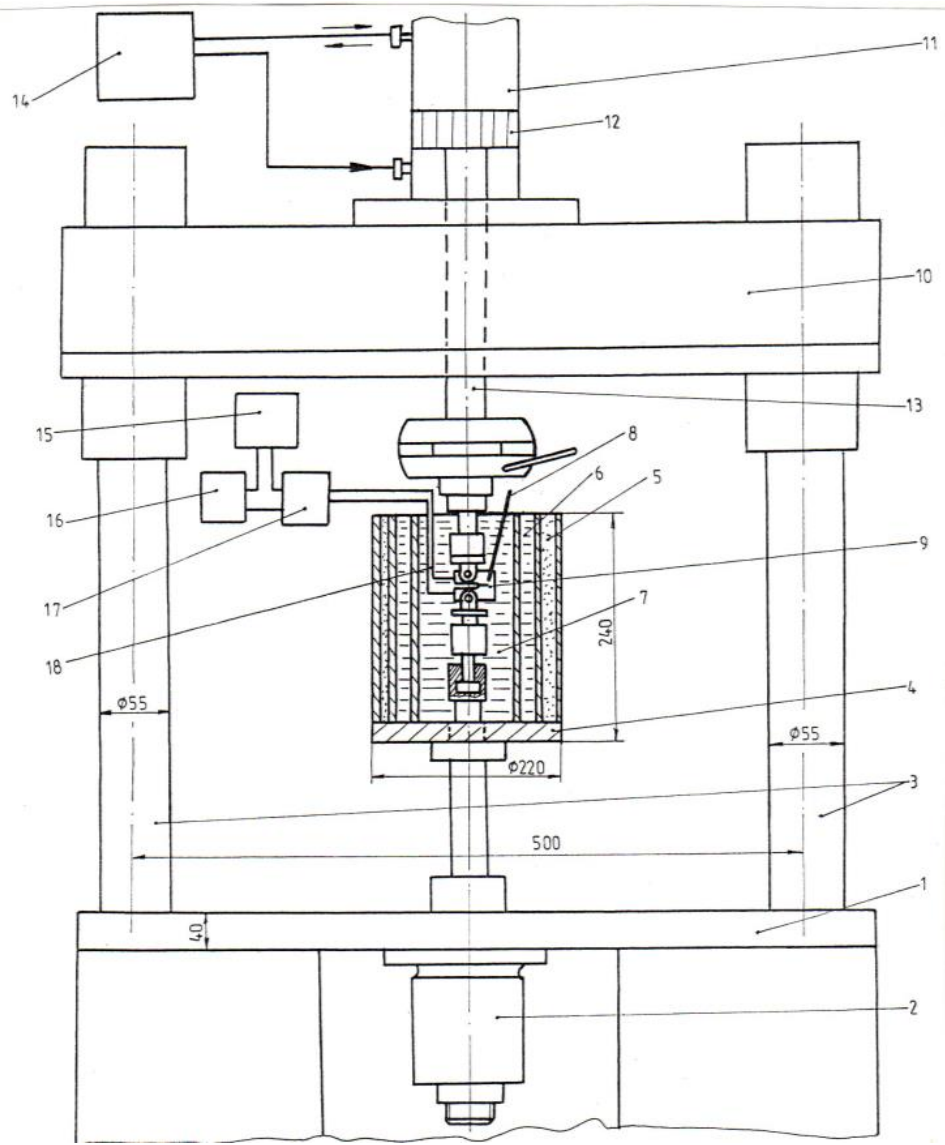

Figure 2: Site testing machine with cold

The maximum loading at the testing machine was of $300 \mathrm{kN}$, with a $5 \mathrm{~Hz}$ frequency. In the 
cryogenic chamber, nitrogen (N2L) was used as cooling agent and ether petroleum as cooling environment [4]. For all the samples, a pre-notch of $2 \mathrm{~mm}$ was firstly applied and the corresponding number of cycles was retained. This moment marks the threshold stress intensity factor $\Delta \mathrm{K}_{\text {th }}$ achievement [3], [4], [7].

The deformations and respectively the crack length variation $\underline{a}_{i}$ at $0.25 \mathrm{~mm}$ gaps measurements were made through the elastic compliance method by using an extensometer mounted on the specimen which is inserted in the cooling chamber [4]. The crack length variation $\underline{a}_{i}$ at $0.25 \mathrm{~mm}$ gaps is marked and the corresponding cycles number $\mathrm{N}_{\mathrm{i}}$. For all the samples, the loading continues until their fracture, moment that concur with the $\mathrm{K}_{\mathrm{c}}$ parameter value, value of the stress intensity factor which represents the fracture tenacity. In this way, on the whole stable crack propagation domain, there are retained the primary data through the values pairs $\left(\mathrm{a}_{\mathrm{i}}, \mathrm{N}_{\mathrm{i}}\right)$.

\section{Theoretical study}

According to the proposed scope and the presented study directions in chapter 1 , there is followed the cracking rate variation da/dN through the told four methods.

$1^{\circ}$. The sequential standardized method

It studies the crack propagation rate da/dN, according to the ASTM E647-2000 American standard, [3], [4], [6], [7]. The method imposes that on the successive gaps of $(2 n+1)$ consecutive experimental data, for which the crack propagation length $\underline{a}$ is approximated through successive parabolicaly curves, for which there is determined the intermediary rate at the middle of each gap. The value $n=3$ is used, and the regression parabolically curve has the expression (1), [3], [4], [6], [7].

$$
\overline{a_{i}}=A_{0}+A_{1} \cdot \frac{N_{i}-C_{1}}{C_{2}}+A_{2} \cdot\left(\frac{N_{i}-C_{1}}{C_{2}}\right)^{2}
$$

The polynomial coefficients $\mathrm{A}_{0}, \mathrm{~A}_{1}$ and $\mathrm{A}_{2}$ are determined from the local approximation condition, respectively the weighting factors $\mathrm{C}_{1}$ and $\mathrm{C}_{2}$ with the formulas (2).

$$
C_{1}=\frac{N_{i-n}+N_{i+n}}{2} \quad C_{2}=\frac{-N_{i-n}+N_{i+n}}{2}
$$

with fulfilling the conditions:

$$
-1 \leq \frac{N_{i}-C_{1}}{C_{2}} \leq 1
$$

If there is considered as a weighting factor the $\mathrm{t}=\mathrm{N}_{\mathrm{i}}-\mathrm{C}_{1}$ in relation which the expression (1) is differentiateing, the crack propagation length is determined for the respective iteration, [3], [6], [7]:

$$
\frac{d a}{d N}=V 1=\frac{A_{1}}{C_{2}}+2 \cdot A_{2} \cdot \frac{N_{i}-C_{1}}{C_{2}^{2}}
$$

The theoretical crack length is calculated with (1) for the respectively gap $\underline{\mathrm{a}}_{\mathrm{i}}$, then the stress intensity factor variation $\Delta \mathrm{K}$, [3], [4], [6], [7], with (5).

$$
\Delta K=\frac{\Delta F}{B \cdot \sqrt{W}} \cdot \frac{2+c}{\sqrt{(1-c)^{3}}} \cdot\left(-5,6 \cdot c^{4}+14,72 \cdot c^{3}-13,32 \cdot c^{2}+4,64 \cdot c+0,886\right)
$$

The expression (5) is an empiric relation, resulted on experimental way and valid for CT specimens, with side notch, loaded at eccentrical tensile test, figure 1. The terms written in (5) are:

- $\Delta \mathrm{F}=\mathrm{F}_{\max }-\mathrm{F}_{\min }$ is the loading variation, in $[\mathrm{N}]$;

- $\quad \mathrm{B}$ - the specimen thickness, in $\mathrm{mm}$;

- $\mathrm{W}$ - the active specimen width, in $\mathrm{mm}$;

- $\quad c=a / W$, is the crack normed length, with fulfilling the condition $c \geq 0.2$. 
The stress intensity factor will result in $\left[\mathrm{Nmm}^{-3 / 2}\right]$. For each group of $(2 \mathrm{n}+1)$ experimental data (each sequence), the next terms will be determined: a, $\Delta \mathrm{K}$ and $\mathrm{V} 1$.

$2^{\circ}$. Paris formula Method

It is generally applied, with good results, on the crack stable propagation domain, [1], [4], [6]. This is given by the relation (6), in which $\mathrm{C}_{2}$ and $\mathrm{m}_{2}$ are material constants.

$$
\frac{d a}{d N}=V 2=C_{2} \cdot(\Delta K)^{m_{2}}
$$

ffNe working procedure is that in some points from the second domain, the V2 rate is the same with V1 from the standardized method, process from which the constants $C_{2}$ and $m_{2}$ are determined. These being known, the V2 rate will be calculated on the whole experimental domain.

$3^{\circ}$. Walker formula method

It consists in the crack growth rate by applying the formula with the same name, relation (7), in its structure the loading asymmetry factor (R) explicitly intervenes, [3], [6], [9].

$$
\frac{d a}{d N}=V 3=C_{3} \cdot \frac{(\Delta K)^{m_{3}}}{(1-R)^{\gamma_{3}}}
$$

in which $C_{3}, m_{3}$ and $\gamma_{3}$ are also constants that depend on the tested material . Similarly to the second method, it is looked up for the logarithm or relation (7) and it is imposed that V3 to be the same as $\mathrm{V} 1$ in at least three points to determined the above constants. There will be determined the V3 rate on the whole experimental data domain.

$4^{\circ}$. NASGRO model [1], [3], [8].

It is known as FNK, abbreviation after the initials of its promoters: Forman - Newman - Konig,

In this case, the cracking rate is determined with (8), obtaining very good results, being also used in the programs NASA/FLAGO, [8].

$$
\frac{d a}{d N}=V 4 \equiv V n=C_{4} \cdot\left[\left(\frac{1-f}{1-R}\right) \cdot \Delta K\right]^{m_{4}} \cdot \frac{\left(1-\frac{\Delta K_{t h}}{\Delta K}\right)^{p_{4}}}{\left(1-\frac{K_{\max }}{K_{c}}\right)^{q_{4}}}
$$

The parameters $\mathrm{C}_{4}$ and $\mathrm{m}_{4}$ correspond to the linear variation of $\mathrm{V} 4$ rate and depend on the specimens material, and $\mathrm{p}_{4}$ and $\mathrm{q}_{4}$ are determined by the graphics curves FCG from the threshold stress intensity factor, $\Delta \mathrm{K}_{\mathrm{th}}$, between the first and second domains, respectively around the value of breaking tenacity $\mathrm{K}_{\mathrm{c}}$, the instability domain between the second and third areas.

Like in the previous cases, there is looked for the logarithm of relation (8) and the V4 rate must be the same with V1 rate in 4 points, determining in this way all the constants from the formula. For R>0, the $\mathrm{f}=\mathrm{R}$ is considered, [8], and the relation (8) becomes:

$$
\frac{d a}{d N}=V 4=V n=C_{4} \cdot[\Delta K]^{m_{4}} \cdot \frac{\left(1-\frac{\Delta K_{t h}}{\Delta K}\right)^{p_{4}}}{\left(1-\frac{K_{\max }}{K_{c}}\right)^{q_{4}}}
$$

Finally, the Vn rate will be determined on the whole experimental loadings domain.

\section{Experimental data processing and conclusions}

By taking into account the paper objective and the proposed study approach methodology, for the three established asymmetry factors $(\mathrm{R}=0.1, \mathrm{R}=0.3$ and $\mathrm{R}=0.5)$, the next sets of calculated values were obtained: 


\section{ACTA UIVERSITATIS CIBINIENSIS - TECHNICAL SERIES}

- $\quad$ (cracking lengths, cracking rates), meaning [a1; V1;V2;V3;Vn];

- (stress intensity factor, cracking rates), with the form $[\triangle \mathrm{K} ; \mathrm{V} 1, \mathrm{~V} 2, \mathrm{~V} 3, \mathrm{Vn}]$.

By using these data, the next graphics were drawn:

- the crack length variation $\mathrm{a}_{1}$ versus the loading cycles number $\mathrm{N}, \mathrm{a}(\mathrm{N})$, for the three asymmetry factors on the same graphic, figure 3;

- the stress intensity factor $\Delta K$ versus the loading number of cycles $N, \Delta K(N)$, for the asymmetry factors on the same graphic, figure 4;

- simultaneously representation, on the same graphic, of the functions: V1(a), V2(a), V3(a) and $\mathrm{Vn}$ (a) for the three asymmetry factors, $\mathrm{R}=0.1$ - figure $5, \mathrm{R}=0.3$ - figure 7 and respectively $\mathrm{R}=0.5$, figure 9;

- simultaneously graphics representation of the functions: V1 $(\Delta K), V 2(\Delta K), V 3(\Delta K)$ and $\operatorname{Vn}(\Delta K)$, for each asymmetry factor, in this way: $R=0.1$, figure $6, R=0.3$, figure 8 , and $R=0.5$, figure 10 .

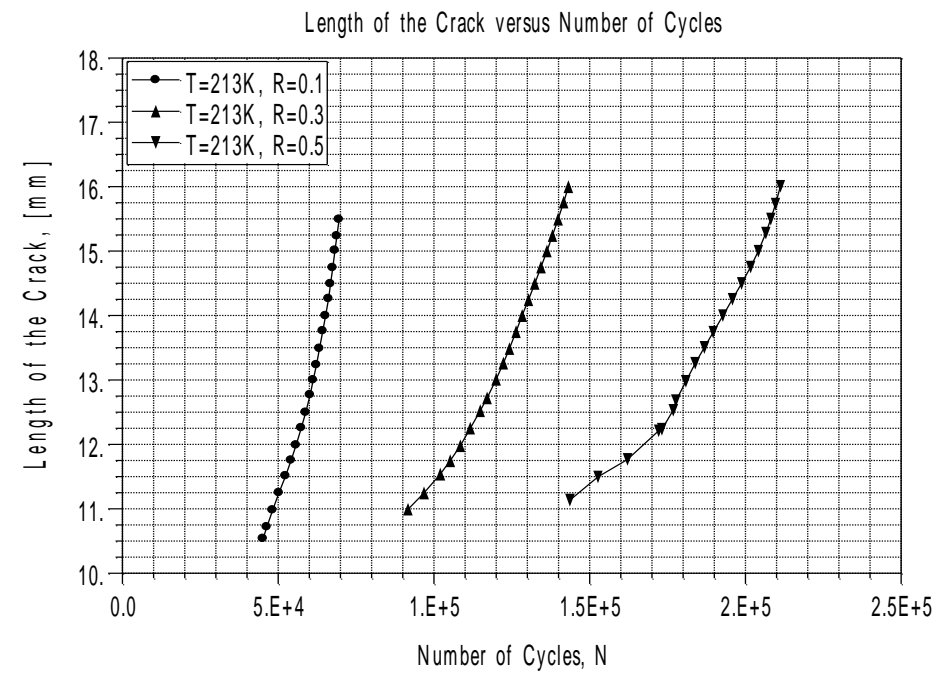

Figure 3: Length of the crack versus number of the cycles

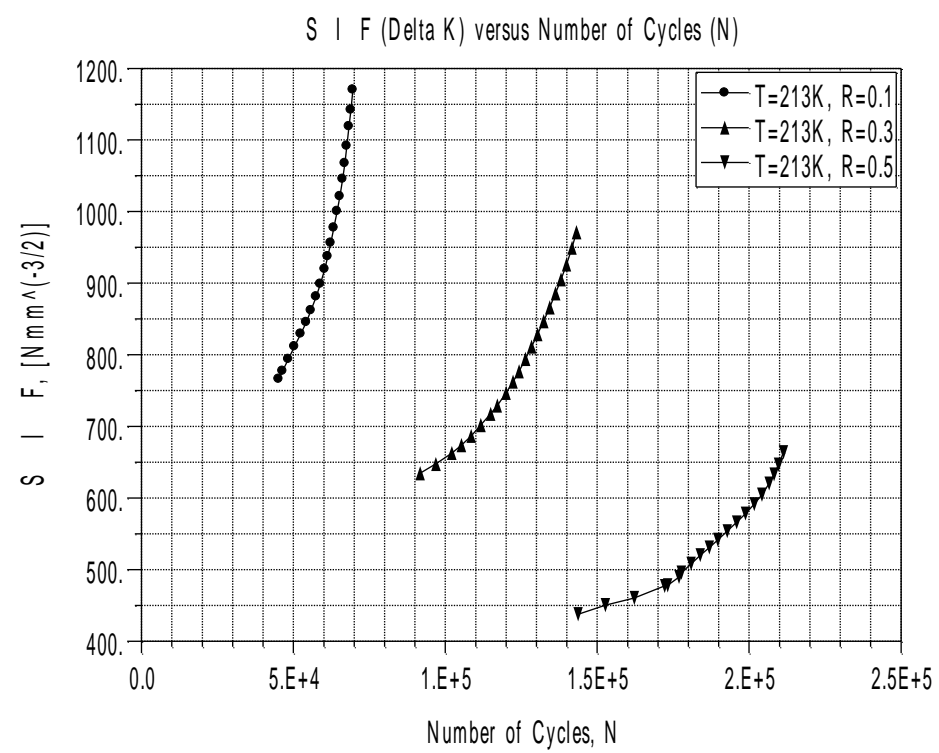

Figure 4: Stress intensity factor versus number of the cycles 
ACTA UIVERSITATIS CIBINIENSIS - TECHNICAL SERIES

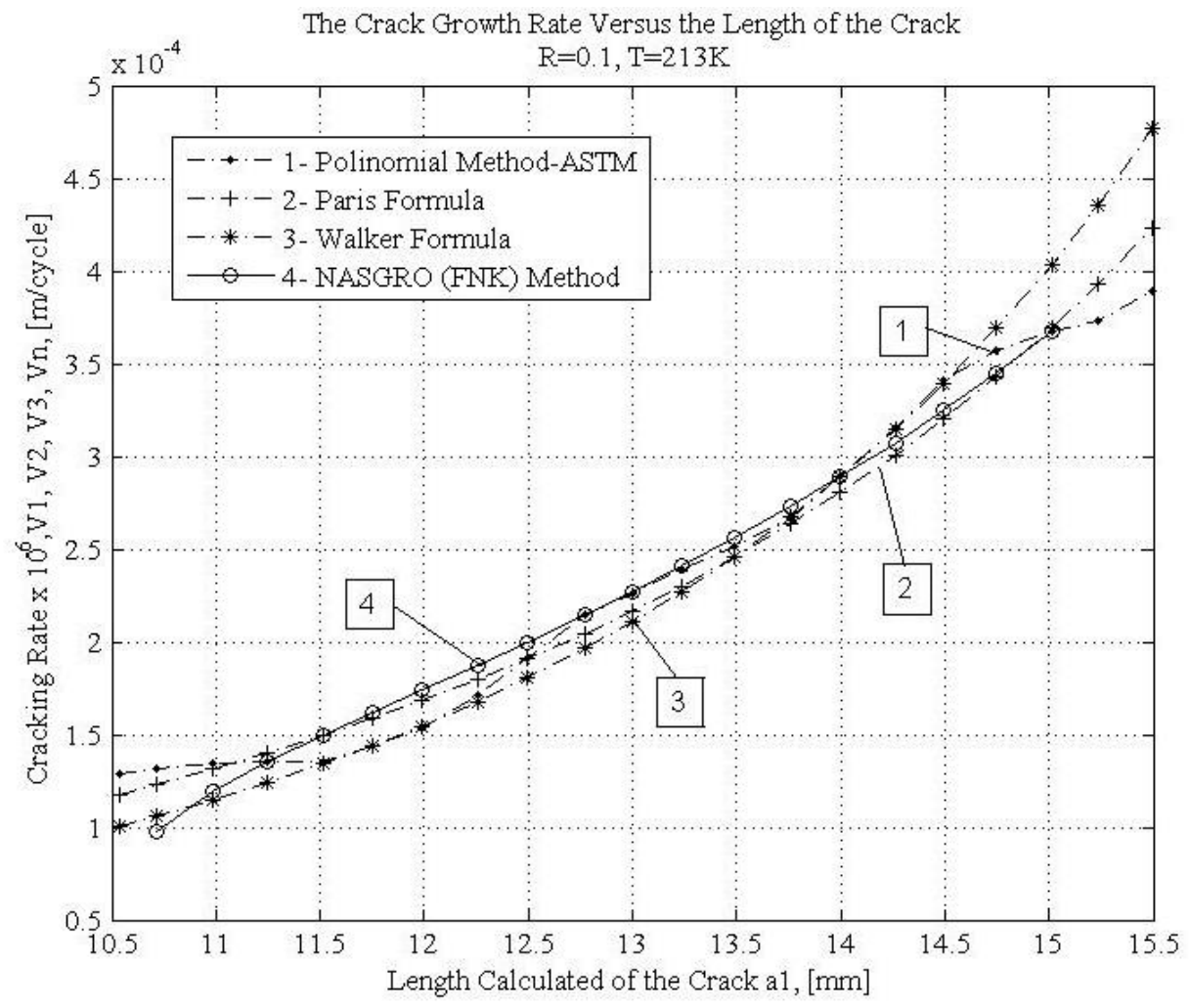

Figure 5: The crack growth rate versus the length of the crack for $R=0.1, T=213 K$

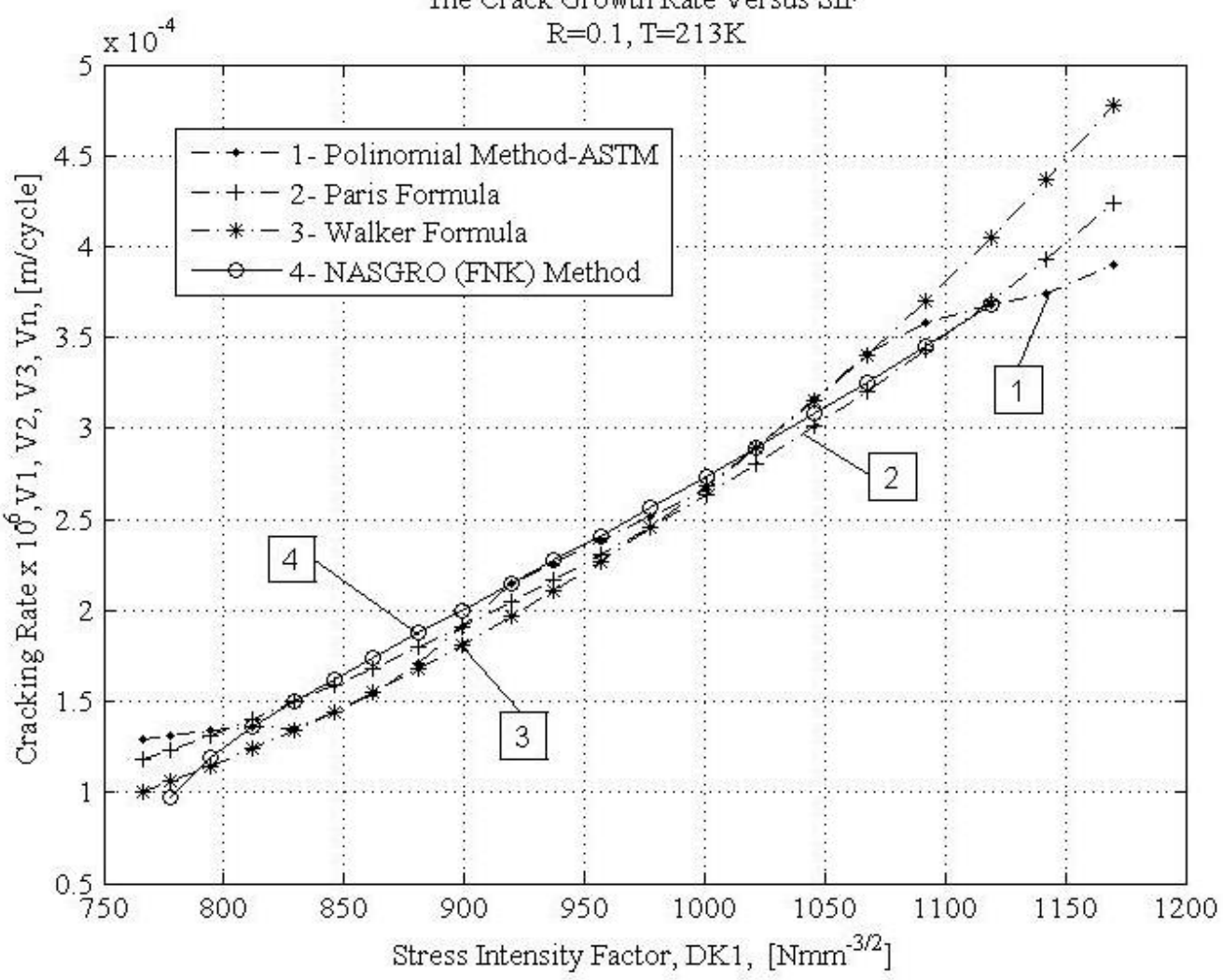

Figure 6: The crack growth rate versus the stress intensity factor for $R=0.1, T=213 K$ 
ACTA UIVERSITATIS CIBINIENSIS - TECHNICAL SERIES

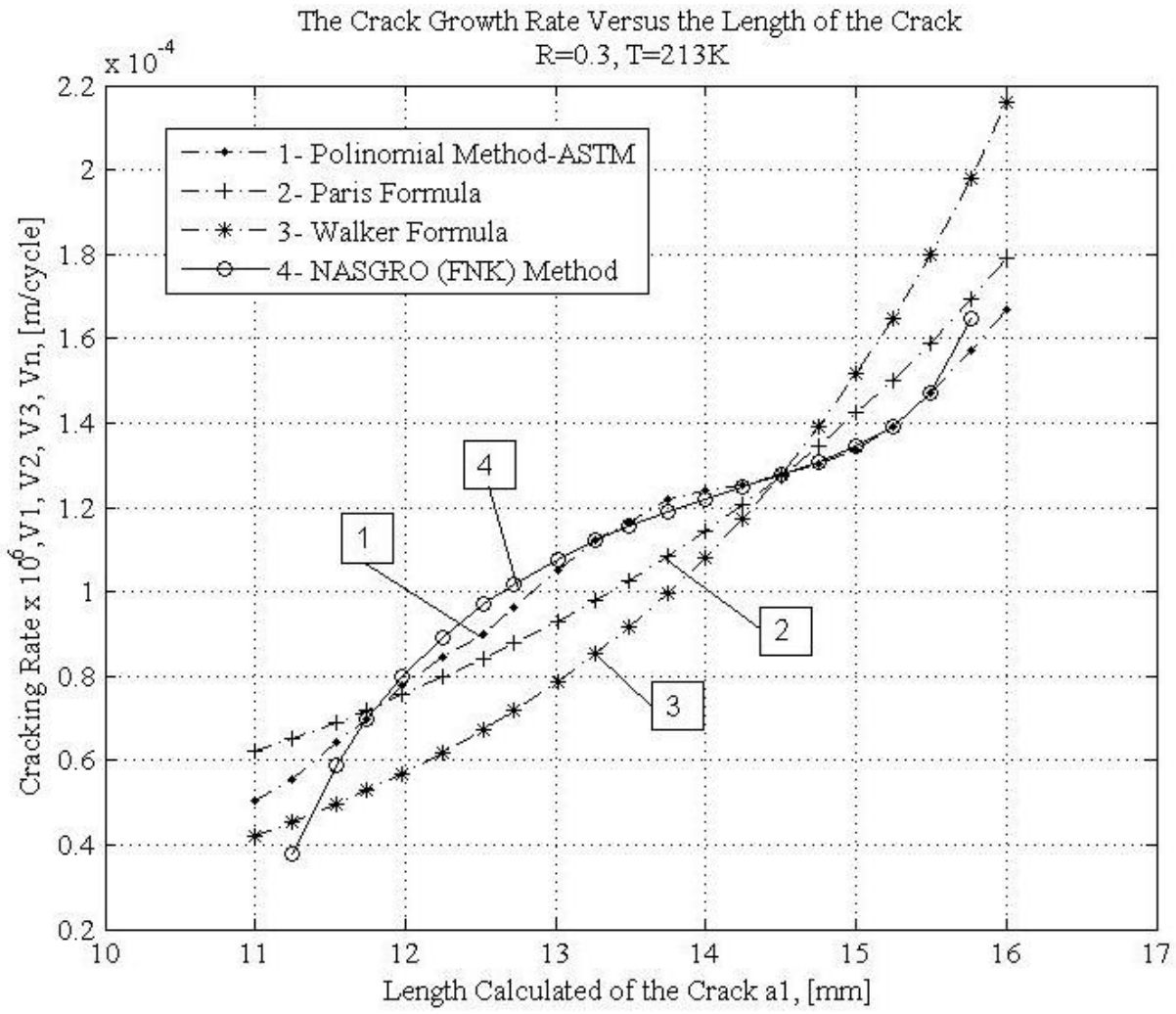

Figure 7: The crack growth rate versus the length of the crack for $R=0.3, T=213 K$

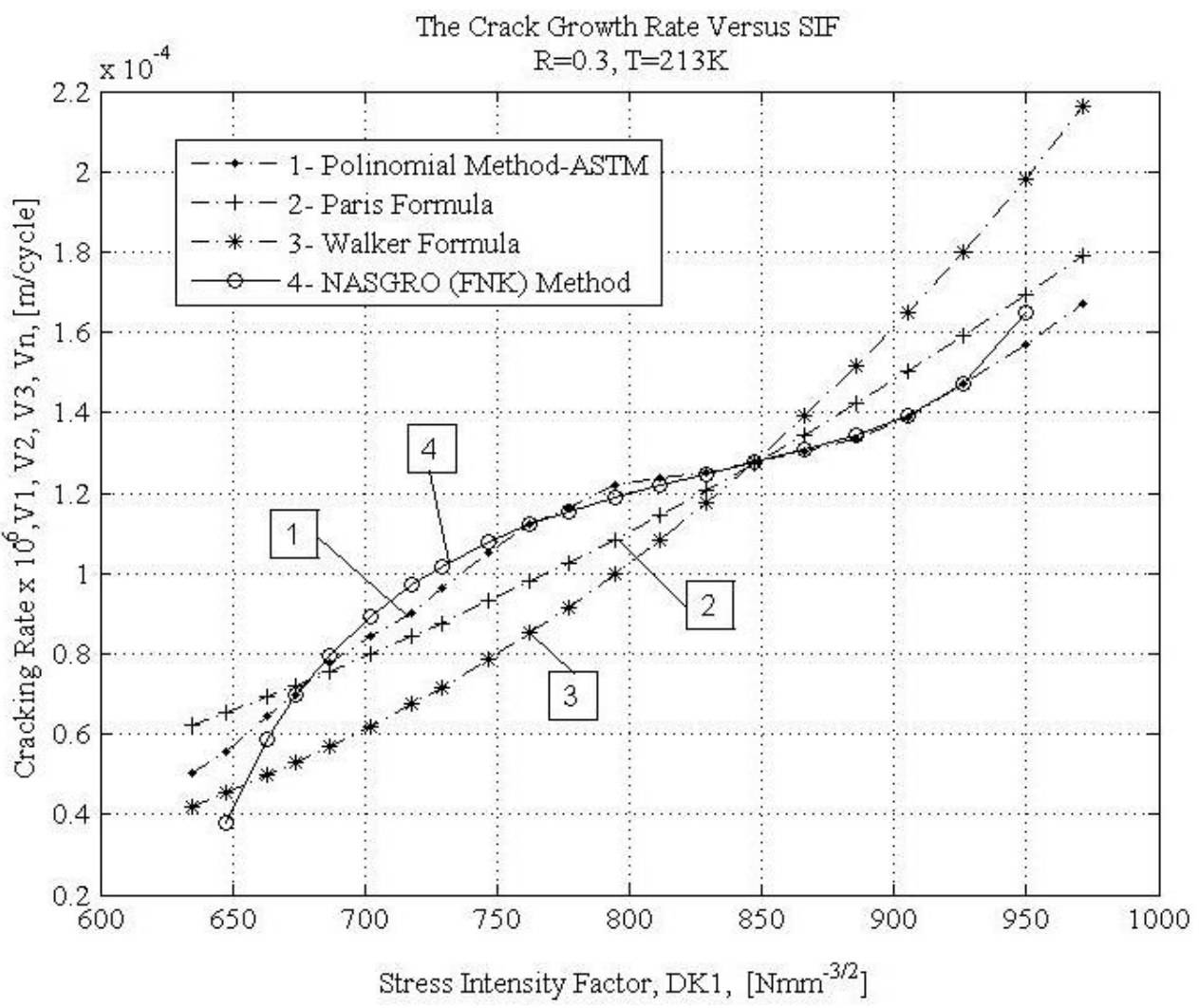

Figure 8: The crack growth rate versus the stress intensity factor for $R=0.3, T=213 K$ 
ACTA UIVERSITATIS CIBINIENSIS - TECHNICAL SERIES

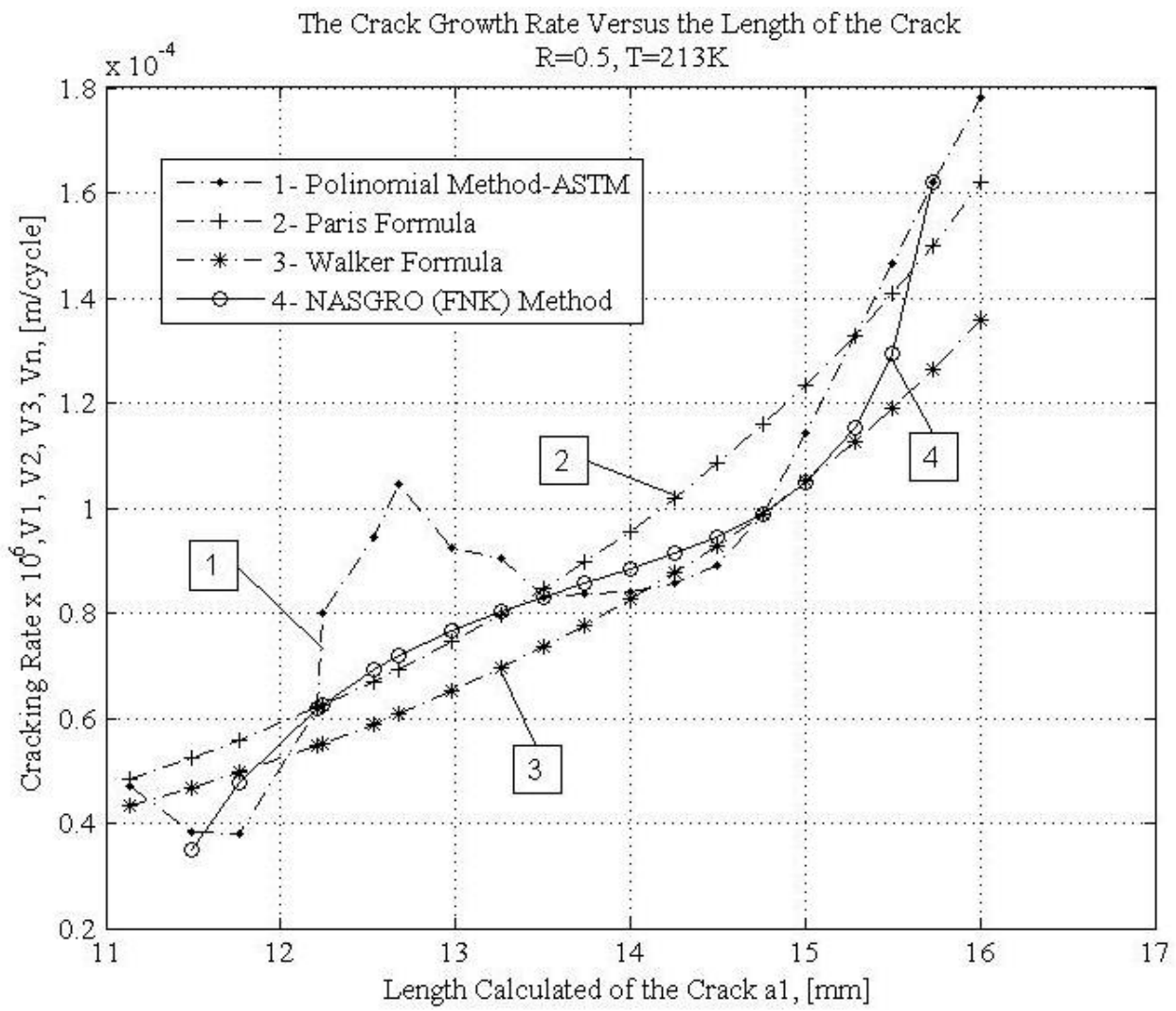

Figure 9: The crack growth rate versus the length of the crack for $R=0.5, T=213 K$

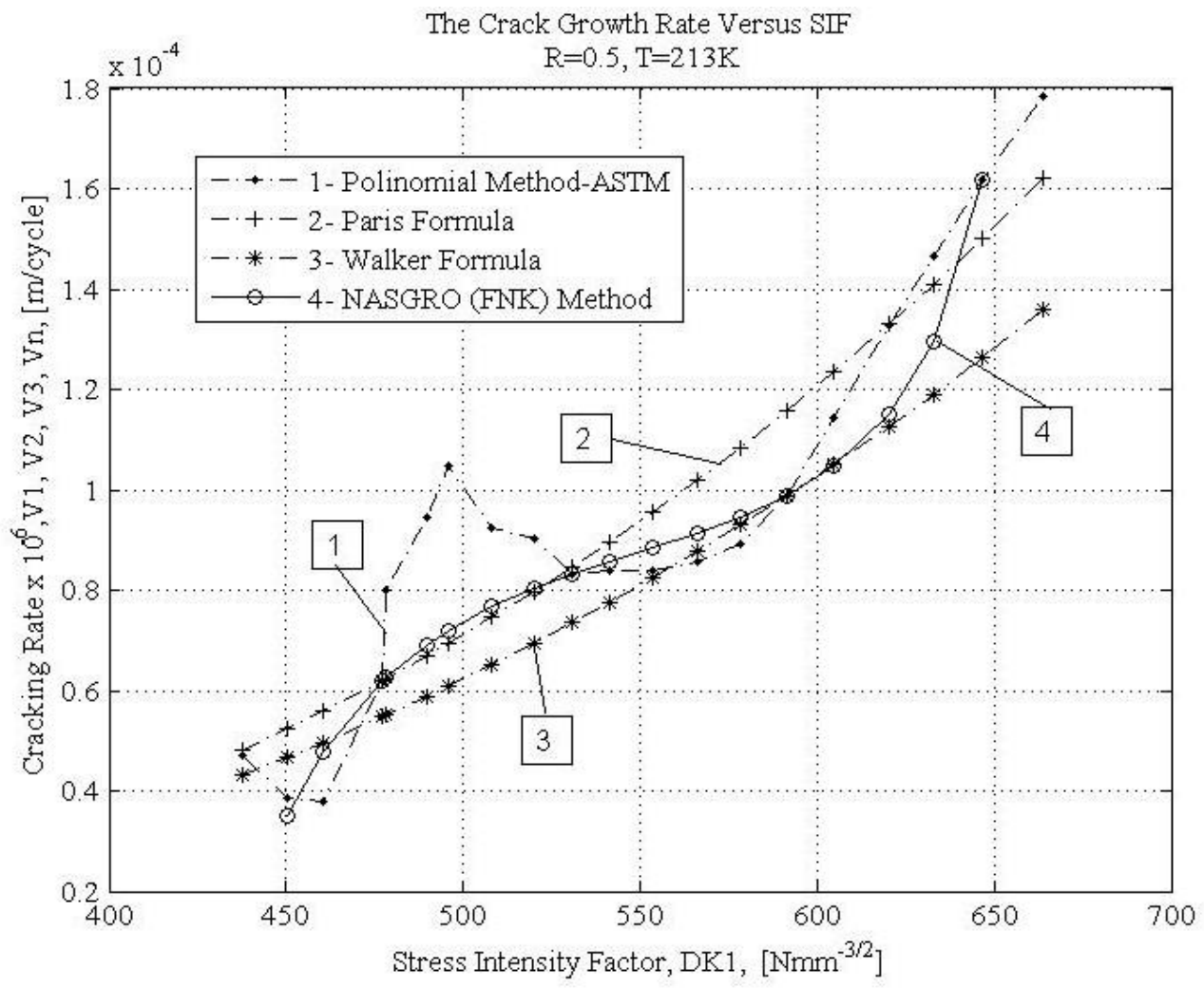

Figure 10: The crack growth rate versus the stress intensity factor for $R=0.5, T=213 K$ 
ACTA UIVERSITATIS CIBINIENSIS - TECHNICAL SERIES

Vol. LXIX 2017

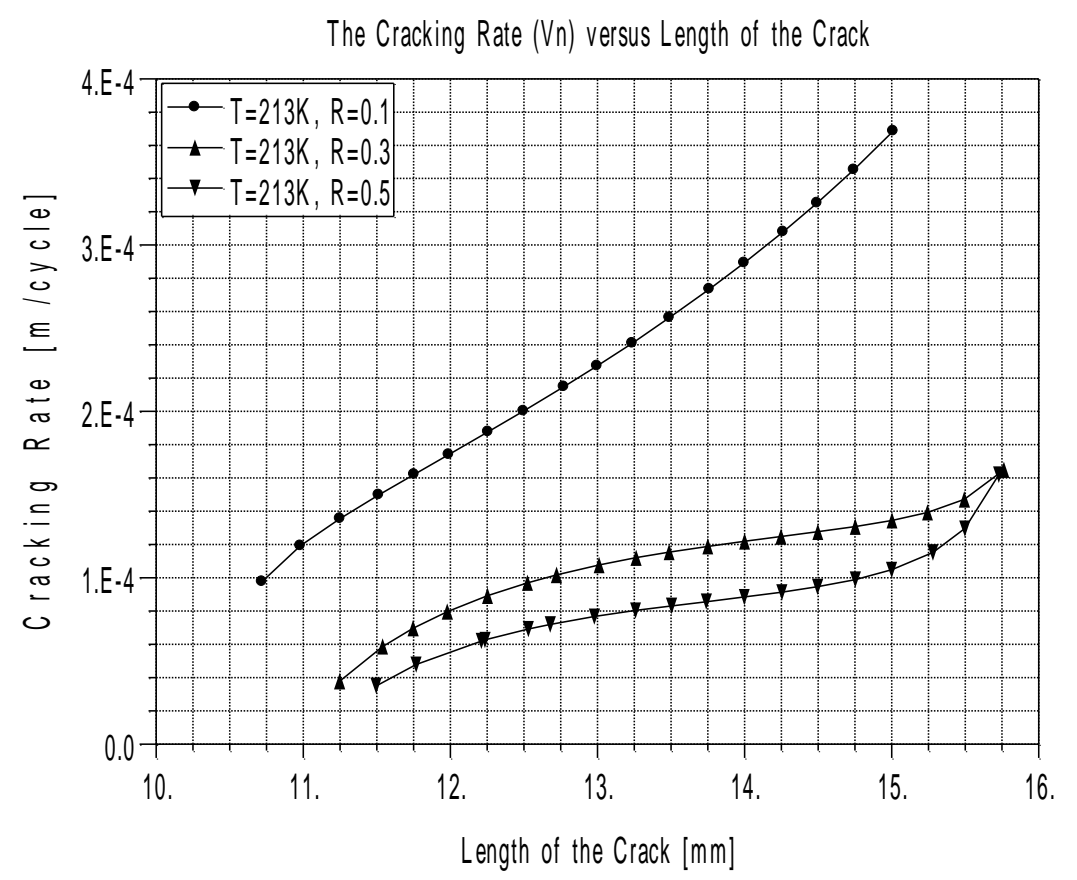

Figure 11: The cracking rate $\mathrm{Vn}$ versus the length of the crack

The Cracking Rate (Vn) versus SIF

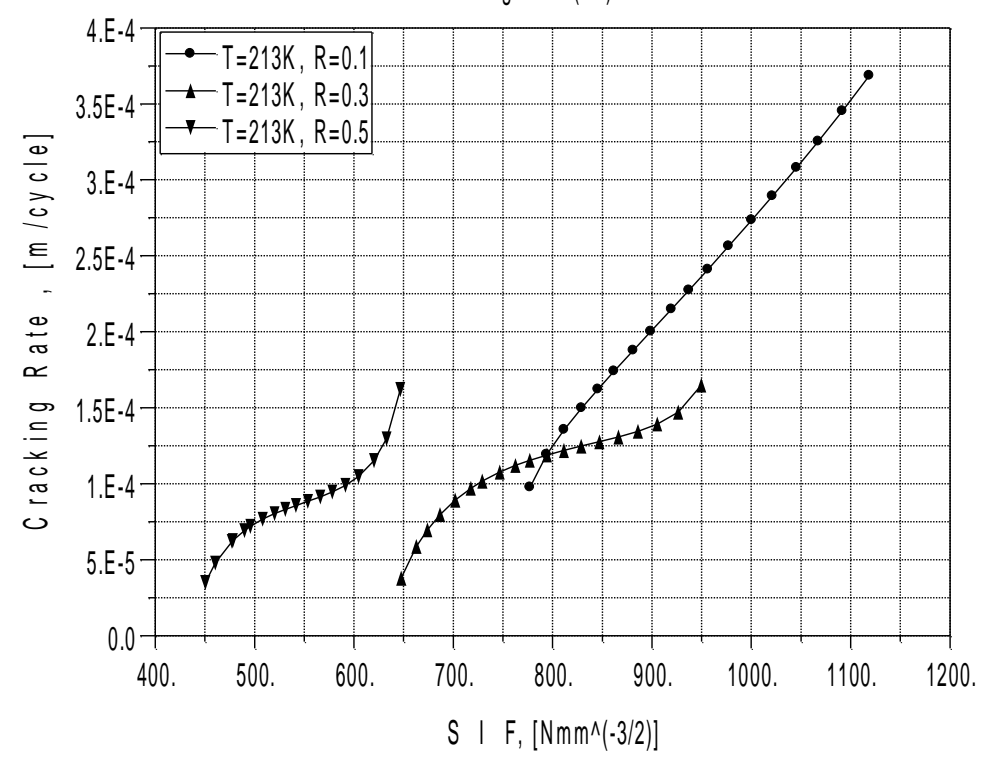

Figure 12: The cracking rate $\mathrm{Vn}$ versus the stress intensity factor conclusions:

From the data arrays and drawn graphics, there are highlightened some more important

* the crack length $\underline{\text { a }}$, on the second propagation domain, is between $10.5 \mathrm{~mm}$ and $16.0 \mathrm{~mm}$, but it is observed that the asymmetry factor increase leads to an increase of the durability domain $\mathrm{N}$, a curves displacement to the right side of the graphic, figure 3;

* the same variation way we also find in the figure 4 for the stress intensity factor variation $\Delta \mathrm{K}$ 
versus the cycles number $\mathrm{N}$, with the observation that an increase of asymmetry factor $\mathrm{R}$ implies the its variation limits decrease;

* in the figures 5 and 6 , for $\mathrm{R}=0.1$, the cracking rates variations $\mathrm{V} 1, \mathrm{~V} 2, \mathrm{~V} 3$ and $\mathrm{Vn}$ are drawn depending on the crack length a, respectively depending on the stress intensity factor $\Delta \mathrm{K}$. The graphics are compact, with the observation that for the crack length limits $(10.5,15.5) \mathrm{mm},(760,1170) \mathrm{Nmm}^{-3 / 2}$ for stress intensity factor, the cracking rates have values between $\left(10^{-4}\right.$ and $\left.4.8^{\cdot} 10^{-4}\right) \mathrm{m} /$ cycle, or $0.1 \mathrm{~mm} /$ cycle and $0.48 \mathrm{~mm} /$ cycle.

* the same graphics are drawn in figure 7 and figure 8 for the asymmetry factor $\mathrm{R}=0.3$. It is observed that at $a=14.5 \mathrm{~mm}$ crack length, figure 7 , respectively for stress intensity factor $\Delta K=850 \mathrm{Nmm}^{-}$ ${ }^{3 / 2}$, figure 8 , all the cracking rates are the same, having the value of $1.27 \cdot 10^{-4} \mathrm{~m} /$ cycle $(0.127 \mathrm{~mm} /$ cycle $)$. The rate Vn has almost the same shape with the V1 rate, and the V3 rate (Walker), close to the specimen fracture, has a rapidly growth. In this case, the stress intensity factor has smaller values and varies approximately between $630 \mathrm{Nmm}^{-3 / 2}$ and $970 \mathrm{Nmm}^{-3 / 2}$.

* for the asymmetry factor $\mathrm{R}=0.5$, the graphics are drawn in figure $9(\mathrm{~V}(\mathrm{a}))$ and figure 10 $(\mathrm{V}(\Delta \mathrm{K}))$. The stress intensity factor (SIF) has values between approximately $480 \mathrm{Nmm}^{-3 / 2}$ and $660 \mathrm{Nmm}^{-}$ $3 / 2$. The crack growth rates are between $3.5 \cdot 10^{-5} \mathrm{~m} /$ cycle $(0.035 \mathrm{~mm} /$ cycle $)$ and $1.78 \cdot 10^{-4} \mathrm{~m} /$ cycle $(0,178$ $\mathrm{mm} /$ cycle). Generally, the curves are grouped with the observation that the V1 rate has a rapidly increase and then follows a gap where it decreases, continuing then with another gap where increases until the specimen breakage.

* by taking into account the paper objective in figure 11 , respectively figure 12 , it is analyzed only the Vn rate variation, by NASGRO method, versus the crack length a, respectively the stress intensity factor $(\Delta K)$ variation, for the three asymmetry factors $(0.1,0.3$ and 0.5$)$, comparative, on the same drawing. The asymmetry factor increase implies a decrease for the cracking rates domain, in this way: - for $\mathrm{R}=0.1$, the $\mathrm{Vn}$ rate is between $9,76 \cdot 10^{-5} \mathrm{~m} /$ cycle and $3,68 \cdot 10^{-4} \mathrm{~m} /$ cycle ; for $\mathrm{R}=0.3, \mathrm{Vn}$ varies between $3,78 \cdot 10^{-5} \mathrm{~m} /$ cycle and $1,65 \cdot 10^{-4} \mathrm{~m} /$ cycle; - for $\mathrm{R}=0.5$, Vn varies in the gap between $\left[3.5 \cdot 10^{-5} \mathrm{~m} /\right.$ cycle, $1,61 \cdot 10^{-4} \mathrm{~m} /$ cycle], figure 11 . The stress intensity factors gaps decrease with the $\mathrm{R}$ factor increase, with the next values: $[777 ; 1119] \mathrm{Nmm}^{-3 / 2}$ for $\mathrm{R}=0.1,[648,970] \mathrm{Nmm}^{-3 / 2}$ for $\mathrm{R}=0.3$, respectively $[450,647] \mathrm{Nmm}^{-3 / 2}$ for $\mathrm{R}=0.5$.

As a final conclusion, we can say that the results obtained with the FNK model are comparable with other ones, especially with the standardized polynomial method ASTM.

\section{References}

1. Constantinescu, D.M., Structural integrity, University "Politehnica" Bucharest, (1998).

2. Dumitru, I., The basis of fatigue calculus, Eurostampa Publishing, Timisoara, (2009)

3. Pană, T., Pastramă, St., D., Mechanicals structures integrity, Fair Partners Publishing House, Bucharest, (2000)

4. Roşca, V., Contributions to the mono-axial fatigue study at low temperatures, Phd. Thesis, University Politehnica of Bucharest, (1997)

5. Roşca, V., The modelling of mechanical structures fracture, Universitaria Publishing, Craiova, (2008).

6. Rusu, O., Teodorescu, M., Laşcu-Simion, N., Materials fatigue, vol. 1 - Calculus basis, vol. 2 - Engineering applications, Technical Publishing House, Bucharest (1992).

7. ASTM E647-95, Standard Test Method for Measurement of Fatigue Crack Growth Rates, American National Standard.

8. Newman, J.C.Jr., Phillips, E.P., Everet, R.A., Fatigue analyses under constant and variable amplitude loading using small-crack theory, NASA/TM-1999-209329, ARL-TR, (2001)

9. E.K. Walker, The effect of stress ratio during crack propagation and fatigue for 2024-T3 and 7076-T6 aluminium. In: Effect of Environment and complex load history on fatigue life, ASTM STP 462, Philadelphia, American Society for Testing and Materials, pp. 1-14, (1970). 